\title{
Predicted Gas-Phase and Liquid-Phase Acidities of Carborane Carboxylic and Dicarboxylic Acids
}

\author{
Josep M. Oliva-Enrich, ${ }^{(\mathrm{a}) *}$ Stephane Humbel, ${ }^{(\mathrm{b})}$ J. Arturo Santaballa, ${ }^{(\mathrm{c}) *}$ Ibon Alkorta, ${ }^{(\mathrm{d})}$ \\ Rafael Notario, ${ }^{(a)}$ Juan Z. Dávalos, ${ }^{(a)}$ Moisés Canle-L., ${ }^{(\mathrm{c})}$ Eduard Bernhardt, ${ }^{(\mathrm{e})}$ \\ Josef Holub, ${ }^{(\mathrm{f})}$ Drahomír Hnyk ${ }^{(\mathrm{f})^{*}}$
}

(a) Physical Chemistry Institute "Rocasolano", CSIC, E-28006 Madrid, Spain (b) Aix Marseille University, CNRS, Centrale Marseille, iSm2, Marseille, France (c) Grupo de Reactividade Química e Fotorreactividade, Departamento de Química, Facultade de Ciencias and CICA, Universidade da Coruña, ES-15071 A Coruña, Spain (d) Instituto de Química Médica, CSIC, Juan de la Cierva 3, E-28006 Madrid, Spain (e) Fakultät für Mathematik und Naturwissenschaften, Anorganische Chemie, Bergische Universität Wuppertal, Gaußstraße 20, 42119 Wuppertal, Germany, (f) Institute of Inorganic Chemistry of the Academy of Sciences of the Czech Republic, v.v.i., 25068 Husinec-Řež, Czech Republic.

\begin{abstract}
By means of MP2 and DFT computations we predict gas-phase acidities and liquid-phase $(\mathrm{MeCN})$ acidities of (di)carboxylic acids derived from icosahedral ortho, meta, and para-carboranes. For comparative purpose, we include the benzoic and phthalic acids. Substitution of benzene by a carborane cage - cage effect - strikingly increases the GA for the (di)carboxylic acids, being the ortho isomers always the most acidic, following the order ortho $>>$ meta $>$ para. The computed GA of the dicarboxylic acid derived from ortho-carborane is far lower than sulphuric acid, due to an enhanced stabilization of the carboxylate through an intramolecular $\mathrm{OHO}$ bridge connection, also taking place in phthalic acid. The change of GA relative to ortho, meta and para positions of the carboxylic groups - isomer effect - is larger for carboranes. As regards to liquid-phase $(\mathrm{MeCN})$, the computations show that carborane (di)carboxylic acids also show a larger acidity as compared to the phthalic acids and that the dicarboxylic orthocarborane is also a superacid in the liquid phase $(\mathrm{MeCN})$, due to the $\mathrm{OHO}$ bridge connection in the carboxylate, as in the gas phase. Additional computations show how much of this isomeric effect is to be attributed to the electronic delocalization.
\end{abstract}


1. Introduction. Chemical reactions can be simply classified as acid/base, redox and electron transfer [1]. The tabulation of chemical data and chemical reactions for organic molecules is very comprehensive and gathered in text [2] and review books [3]. The combination of inorganic polyhedral heteroboranes [4] with organic moieties is less explored [5]. Given the polyhedral nature of heteroborane molecules - in this work carborane mono- and dicarboxylic acids respectively - from a chemical reactivity point of view, transferability is more difficult to define for these compounds [6]. Therefore, tabulation of acid/base properties of (di)acids derived from heteroboranes may give more insight into the prediction of reaction mechanisms with other organic molecules, such as amino acids, proteins and biomolecules in general [7]. We should also emphasize that heteroboranes are not found in Nature. Returning to the acid/base reactions, the gas-phase acidity (GA) is the ease (driving force) for a molecule AH to release a proton $\mathrm{H}^{+}$[8]. The lower the value of $G A$, the larger the acidity. A superacid is an A-H system able to release a proton more easily than in sulphuric acid $\mathrm{H}_{2} \mathrm{SO}_{4}$, the latter with $\mathrm{GA}=\Delta_{\mathrm{r}} \mathrm{G}^{0}=1265 \mathrm{~kJ} \cdot \mathrm{mol}^{-1}$ [9]. For instance, a recent research issue is to define the strongest acid using a common icosahedral (car)borane frame $\left(\mathrm{B}_{12} \mathrm{X}_{12}\right)^{2}-[10$, $11,12]$ and $\left(\mathrm{HCB}_{11} \mathrm{X}_{11}\right)^{-}[13,14,15,16]$. The protic acids derived from these moieties are expected to be superacids, able to protonate neutral molecules and thus act as Brønsted-Lowry acids [17]. On the other hand, the Hammett acidity function $\left(\mathrm{H}_{0}\right)$ is a measure of acidity that is used for very concentrated solutions of strong acids, including superacids and is the best-known acidity function used to extend the measure of Brønsted-Lowry acidity beyond the dilute solutions for which the $\mathrm{pH}$ scale is useful $[18,19]$.

In this work we study the molecules derived from substituting hydrogen atoms in carborane $\mathrm{C}-\mathrm{H}$ bonds by carboxylic groups $\mathrm{COOH}$, in icosahedral ortho, meta, and para carboranes and predict, by means of quantum-chemical computations, gas-phase (GA) and liquid-phase $(\mathrm{MeCN})$ acidities $\left(p \mathrm{~K}_{a}\right)$. In order to compare these properties we also include the benzene anologues with one or two carboxylic groups in different positions, namely, benzoic acid, phthalic (ortho), isophthalic (meta), and terephthalic (para) acids. We would also like to highlight the differences in the properties of molecules when subtituing (2D) benzene rings by carboranes (3D) cages [20]. The structures of the compounds included in this work are displayed in Figure $1 \& 2$ (see also Supplementary Information - SI - for the corresponding optimized geometries). At this point, we 
should emphasize that in a recent work [21], we measured (and computed) a gas-phase acidity (GA) of $1325(1321) \mathrm{kJ} \cdot \mathrm{mol}^{-1}$ for (2a, Figure 1) the carboxylic acid derived from icosahedral meta-carborane 1-(COOH)-1,7- $\mathrm{C}_{2} \mathrm{~B}_{10} \mathrm{H}_{11}$. However, as we will discuss below, these experiments could not be carried out for the carborane dicarboxylic acids, due to the much larger acidity of the latter. Finally, a delocalization energy analysis of the compounds included in this work is also carried out in order to assess the role of the delocalization of the four $\pi$ electrons of the carboxylic moieties with respect to the acidity.

Labelling of the compounds: The labels for the compounds included in this work are chosen as follows, as shown in Figures 1 \& 2: \#a labels a carborane carboxylic acid; \#b labels the anion (carboxylate) derived from \#a by deprotonation of the carboxylic group; \#c labels a carborane dicarboxylic acid; \#d labels a carboxylate derived from \#c by deprotonation of one of the carboxylic groups; \#e labels a dicarboxylate derived from \#d by deprotonation of the second carboxylic group; Numbers $\#=\{\mathbf{1}, \mathbf{2}, \mathbf{3}\}$ refer to \{ortho, meta, para\} respectively. As for the benzoic acid and its deprotonated (benzoate) form we use labels $\mathbf{4 a}$ and $\mathbf{4 b}$ respectively. For dicarboxylic acids derived from benzene - phthalic, isophthalic and terephthalic acid - we use the labels $\mathbf{4 \$ , 5}$, and $\mathbf{6} \mathbf{\$}$, respectively, following $\$=\{\mathbf{c}, \mathbf{d}, \mathbf{e}\}$ for $\{$ neutral, carboxylate, dicarboxylate $\}$, respectively, referring to first and second deprotonation of the carboxylic moieties.

\section{Computational Methodology}

All computations in this work related to gas-phase (GA) and liquid-phase $\left(\mathrm{pK}_{\mathrm{a}}\right)$ acidities were carried out with the suite of programs Gaussian09 [22]. As theoretical methods for the gas-phase computations, we used Møller-Plesset $2^{\text {nd }}$-order perturbation theory (MP2) [23] and hybrid HF-DFT methods with the B3LYP functional [24, 25] and basis set $6-311+G(d, p)$, which is of triple- $\zeta$ quality, with polarization functions for all atoms and diffuse functions for boron and carbon. The thermochemistry of neutral molecules, monoanions and dianions in the gas phase were computed as the contribution of the electronic energy -nuclear repulsion included- $\left(\mathrm{E}_{\mathrm{el}}\right)$, the zero point vibrational energy (ZPE) and the computed thermal energy, enthalpy and Gibbs energy change from $\mathrm{T}=$ $0^{\circ} \mathrm{K}$ to the working temperature $\mathrm{T}=298.15^{\circ} \mathrm{K}\left(\Delta \mathrm{G}^{0} \rightarrow 298.15^{\circ} \mathrm{K}\right)$, i.e.:

$X_{(g)}^{0}=E_{e l}+Z P E+X_{0^{\circ} K \rightarrow 298.15^{\circ} \mathrm{K} K}^{0}$ 
with $\mathrm{X}=\{E, H, G\}$ for energy, enthalpy and Gibbs energy respectively.

As regards to liquid-phase computations $(\mathrm{MeCN})$, the $p \mathrm{~K}_{\mathrm{a}}$ values were obtained using the thermodynamic cycle shown in Scheme 1 below, following the strategy of Psciuk et al.[26].

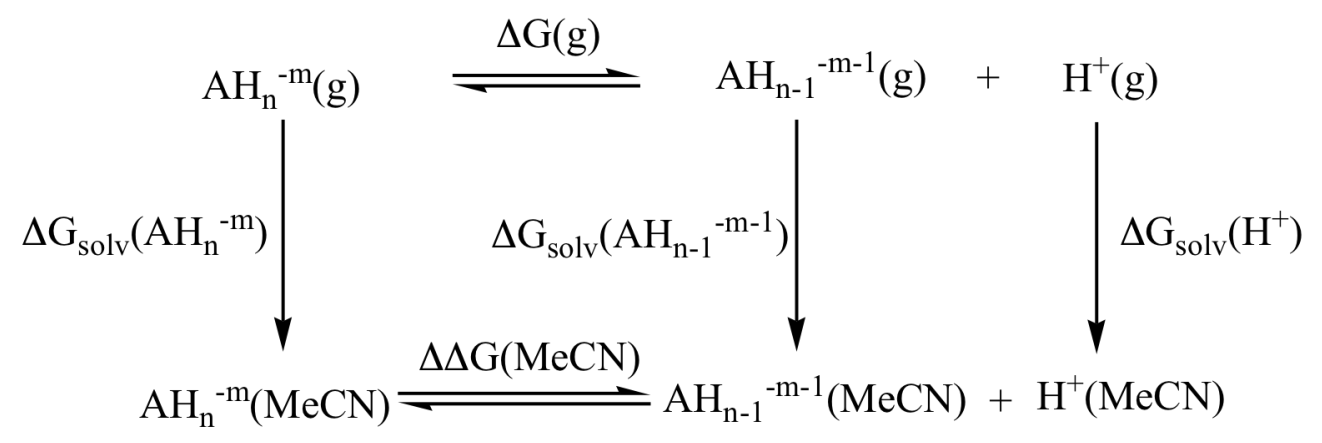

Scheme 1. Thermodynamic cycle used for $p \mathrm{~K}_{\mathrm{a}}$ computations in $\mathrm{MeCN}$ ( $n$ stands for the number of acidic protons and $m$ for the charge).

The solvation contribution was obtained as the difference between the electronic energy of the optimized structures of the neutral species, monoanions and dianions in the gas phase and in solution. $\mathrm{pK}_{\mathrm{a}} \mathrm{s}$ in acetonitrile were computed using the SMD implicit solvation model [27]. Solvation free energies were computed at the SMD/B3LYP/6$31++\mathrm{G}(\mathrm{d}, \mathrm{p})$ and SMD/B3LYP/6-311+G(d,p) level of theory; Gaussian default values [22] were used for solvent parameters. The change of standard state, from 1 atm to 1 $\mathrm{mol} \cdot \mathrm{L}^{-1}$, was included in the $\mathrm{pK}_{\mathrm{a}}$ computations, and the number of equivalent protonation/deprotonation sites was also taking into account. For $\mathrm{pK}_{\mathrm{a}}$ computations in solution, the absolute free energy of the solvated proton is a critical parameter, usually computed as the contribution of the absolute free energy of the proton in the gas-phase at standard temperature and pressure $\left(-26.28 \mathrm{~kJ} \cdot \mathrm{mol}^{-1}\right.$ at $\left.298.15^{\circ} \mathrm{K}\right)$, which is obtained with the Sackur-Tetrode equation [28], and the Gibbs energy of proton solvation in $\mathrm{MeCN}\left[\mathrm{H}^{+}(\mathrm{g}) \rightarrow \mathrm{H}^{+}(\mathrm{MeCN})\right]$. We use a value of $1067.34 \mathrm{~kJ} \cdot \mathrm{mol}^{-1}$ for the proton solvation in $\mathrm{MeCN}$ [29].

An alternative way for the computation of the $\mathrm{pK}_{\mathrm{a}}$ 's is by use of the Gibbs energy of the optimized structures of the neutral species, the monoanions and the dianions in solution together with the Gibbs energy of the proton solvation (as above), e.g. for the acid-base equilibrium: 


$$
\mathrm{AH}_{2}(\mathrm{MeCN}) \rightleftarrows \mathrm{AH}^{-}(\mathrm{MeCN})+\mathrm{H}^{+}(\mathrm{MeCN})
$$

and the corresponding $\mathrm{pK}_{\mathrm{a}}$ is given by the following equation:

$$
p K_{a}=\frac{\Delta \Delta G^{*}}{2.3 \cdot R \cdot T}=\frac{\left[G_{A H^{-}}^{*}(M e C N)+\Delta G_{H^{+}}^{*}(M e C N)\right]-G_{A H_{2}}^{*}(M e C N)}{2.3 \cdot R \cdot T}
$$

with the superscript “*” referring to a standard state of one mole per liter.

The geometries of all molecules (neutral, anions and dianions) were optimized to stationary points corresponding to energy minima in their corresponding potential energy hypersurfaces. The optimized geometries of the structures included in this work and the computed $p \mathrm{~K}_{a}$ 's at the SMD/B3LYP/6-311+G(d,p) level of theory are gathered in the SI. Minima search for anions of meta- and para- isomers of carborane monocarboxylic acids (2b and $\mathbf{3 b}$ ) in $\mathrm{MeCN}$ failed, computed at both the SMD/B3LYP/6-31++G(d,p) and SMD/B3LYP/6-311+G(d,p) levels of theory; therefore those $p \mathrm{~K}_{\mathrm{a}}$ 's were calculated using the minima found in the gas phase and the corresponding solvation energy as computed with the Gaussian09 package. Obtained values should be basically right as geometries in the gas phase should be similar in acetonitrile.

As for the delocalization energies, we used the BLW formalism [30] in the computations with a modified version of the GAMESS program [31] at the B3LYP level of theory and the $6-311+\mathrm{G}(\mathrm{d})$ basis set $[24,25,32]$. In this particular case, we avoid the use of polarization $p$-functions on hydrogen in order to avoid spurious $\pi$ orbitals on these atoms. As implemented in GAMESS, the B3LYP formalism uses the VWN5 correlation functional [33]. We should emphasize that when the four electrons of the acidic moieties are constrained to be located on the $\pi$ atomic orbitals of the acidic moieties, the remaining electrons of the system are restrained and cannot delocalize on these moieties, thus making a strict localization constraint.

\section{Results and Discussion.}

\subsection{Gas-phase acidities (GA)}

The results from electronic structure computations and computed GA are gathered in Table 1 for icosahedral carborane (di)carboxylic acids, together with the corresponding (di)carboxylate species, 1a thru 3e. In Table 2 we display these values for benzoic and 
phthalic acids and the corresponding (di)carboxylate forms 4a thru 7e. In Figure 1 and Figure 2 we display the optimized structures of these molecule for the carborane and benzoic/phthalic acids respectively, using the MP2/6-311+G(d,p) level of theory. All geometries correspond to energy minima at this level of theory. The Cartesian coordinates of the optimized geometries of all molecules included in this work are gathered in the Supporting Information (SI). We should emphasize that in order to follow the differences and strengths between (di)acids, the lower the value of GA, the larger the gas-phase acidity, or ease for proton detachment. The GAs are always reported in $\mathrm{kJ} \cdot \mathrm{mol}^{-1}$.

In Table 1 we gather the GA of the ortho (1a), meta (2a) and para-carborane (3a) carboxylic acids, the major difference being for the ortho acid, when compared to the meta and para analogues, see also Figure 3. Note that these GA correlate with the experimental dipole moments of $4.53,2.85$, and 0.0 , respectively, for the simple icosahedral ortho-carborane, meta-carborane and para-carborane. ${ }^{34}$ Hence orthocarborane acid 1a is much more acid (by $\approx 40 \mathrm{~kJ} \cdot \mathrm{mol}^{-1}$ !) than the meta analogue $\mathbf{2 a}$, being the latter more acid to a lesser extent (by $7 \mathrm{~kJ} \cdot \mathrm{mol}^{-1}$ ) than the para analogue 3a. In other words, the ionization constant for the ortho acid 1a is hugely (exponentially) larger as compared to the meta and para acids. If we change the carborane cage (3D) by a benzene ring (2D) we have the benzoic acid - Figure 2, Table 2 - with GA(4a) $=1390$ $\mathrm{kJ} \cdot \mathrm{mol}^{-1}$ (comp) / $1394 \mathrm{~kJ} \cdot \mathrm{mol}^{-1}$ (exp), with a much larger GA. Therefore, in the gas phase, the carborane monocarboxylic acids 1a, 2a and 3a are much more acidic than the benzoic acid by $110 \mathrm{~kJ} \cdot \mathrm{mol}^{-1} !$ !, $70 \mathrm{~kJ} \cdot \mathrm{mol}^{-1}$, and $65 \mathrm{~kJ} \cdot \mathrm{mol}^{-1}$ respectively, hence what we call a carborane cage effect. The fact that the midpoint of the $\mathrm{C}-\mathrm{C}$ and $\mathrm{C} \cdots \mathrm{C}$ vectors in the ortho- and meta-carborane, respectively, is a center of the positive charge ${ }^{35}$ might be considered as a driving force for it since the dipole moment of benzene is zero. Substitution of benzene by an icosahedral carborane cage turns into a huge increase of gas-phase acidity GA, with a striking increase for the ortho acid.

Substitution of the hydrogen atom in the cage $\mathrm{C}-\mathrm{H}$ bond in carborane carboxylic acids 1a, 2a and 3a turns into dicarboxylic acids, 1c, $2 \mathbf{c}$ and 3c. The presence of a second carboxylic group involves a considerable lowering of GA - acidity enhancement - by $60 \mathrm{~kJ} \cdot \mathrm{mol}^{-1}$ !, $15 \mathrm{~kJ} \cdot \mathrm{mol}^{-1}$ and $8 \mathrm{~kJ} \cdot \mathrm{mol}^{-1}$, for the ortho, meta and para-carborane isomers respectively - see Table 1 and Figure 3. The enhanced acidity for the ortho 
dicarboxylic acid (1c) is due to the $\mathrm{O} \cdots \mathrm{H} \cdots \mathrm{O}$ bridge interaction, as shown in Figure 5. Note that if we use an alternative carboxylate anion structure (1d) without the bridge interaction, the GA goes up by $50 \mathrm{~kJ} \cdot \mathrm{mol}^{-1}$. Hence, we should consider the orthocarborane dicarboxylic acid (1c) as a superacid, with a GA(1c) $=1221 \mathrm{~kJ} \cdot \mathrm{mol}^{-1}$, far beyond $\mathrm{H}_{2} \mathrm{SO}_{4}$ with a difference of $45 \mathrm{~kJ} \cdot \mathrm{mol}^{-1}$. Again, substitution of the carborane cage (3D) by a benzene ring (2D) in the dicarboxylic carborane acids, implies an increase of GA by $70 \mathrm{~kJ} \cdot \mathrm{mol}^{-1} ! !, 63 \mathrm{~kJ} \cdot \mathrm{mol}^{-1}$ and $50 \mathrm{~kJ} \cdot \mathrm{mol}^{-1}$ for the ortho, meta and para benzoic analogues: phthalic acid (5c), isophthalic acid $(\mathbf{6 c})$ and terephthalic acid (7c) - Figure 3 and Figure 4. Hence, again, the cage effect as in the monocarboxylic carborane acids: dicarboxylic carborane acids are more acidic than phthalic acids, with the ortho isomer always the most acidic. Note that $\mathrm{GA}_{1}{ }^{\text {ortho }}(\mathbf{1 c})$ is strikingly lower than in sulphuric acid, $\mathrm{GA}\left(\mathrm{H}_{2} \mathrm{SO}_{4}\right)=1265 \mathrm{~kJ} \cdot \mathrm{mol}^{-1}$ ! and hence 1c can be considered a superacid. This fact explains why measuring acidities in the gas-phase at the Physical Chemistry Institute (CSIC) could not be carried out for the carborane dicarboxylic acids $1 c, 2 c$ and $3 c$ !

We now turn to the carborane carboxylate anions $\mathbf{1 d}, \mathbf{2 d}$ and $\mathbf{3 d}$, and the phthalic analogues $5 \mathbf{d}, \mathbf{6 d}$ and $7 \mathbf{d}$. Analysis of the GA for the monocarboxylates show that the acidity order is inverted, as compared to the dicarboxylic acids, as shown in Figure 3 and Figure 4. The deprotonation of a dicarboxylic acid in the gas-phase involves a charge density redistribution which strengthens the remaining $\mathrm{O}-\mathrm{H}$ bond from the carboxylic group, hence the much larger $\mathrm{GA}_{2}$, as compared to GA. The $\mathrm{GA}_{2}$ lowerings are more significant for the ortho isomers in the acid anions, as opposed to the diacid neutral systems, again due to the hydrogen intramolecular interaction between the two carboxylate groups. Therefore there is an inverted isomer effect for the deprotonated systems. The cage effect remains unaltered in the carborane anions, with larger $\mathrm{GA}_{2}$ in the phthalic anions, as compared to the carboranes, for a given isomer. A summary of the results and the discussion of this section is displayed in Figure 3 and Figure 4, where the most acidic systems are encircled with a dashed line, namely, the ortho-carborane dicarboxylic superacid (1c) - most acidic system in this work - and phthalic acid (5c). Hence combination of organic and inorganic moieties within boron chemistry may result in interesting and unexpected acid behavior. 


\subsection{Liquid-phase acidities.}

The instability of carborane carboxylic and dicarboxylic acids in aqueous solution precludes the determination of the acidity in this solvent; therefore the corresponding $\mathrm{pK}_{\mathrm{a}}$ values were computed in acetonitrile $(\mathrm{MeCN})$ as a solvent. The dielectric constant of $\mathrm{MeCN}(\varepsilon=36.0)$ is smaller than that of water (78.5), [36] the same applies to the autoprotolysis constant $\left(\mathrm{pK}_{\text {autoprotolysis }}(\mathrm{MeCN}) \geq 33\right.$ ), [37] which implies that $\mathrm{MeCN}$ has low basicity and extremely low acidity, and as a result it shows a limited capacity to stabilize anions by hydrogen bonding [36]. All this leads to higher $\mathrm{pK}_{\mathrm{a}}$ values in $\mathrm{MeCN}$ in comparison to aqueous solution.

The results obtained using both the thermodynamic cycle (Scheme 1 above) and the direct computations of Gibbs energies (Equation 3) of the optimized structures in solution are shown in Table 3 and Table S2 of the Supplementary Information. The values obtained are very similar, with differences within one $\mathrm{pK}_{\mathrm{a}}$ unit.

The computed $\mathrm{pK}_{\mathrm{a}}$ for benzoic acid is similar to other values found in the literature, both experimental and theoretical, and thus are expected the remaining computed values. The first deprotonation $\left(\mathrm{pK}_{\mathrm{a}, 1}\right)$ should match the experimental acidity constants within one $\mathrm{pK}_{\mathrm{a}}$ unit, which also holds for isophthalic and terephthalic acids. In acetonitrile the general trend is similar, as compared to the gas phase; the carborane cage has an acidifying effect due to the different electronic distribution as mentioned above.

Table 3. $\mathrm{pK}_{\mathrm{a}}$ values from quantum-chemical computations, for the compounds studied in this work, using the SMD/B3LYP/6-311+G(d,p) model ${ }^{\mathrm{a}}$, MeCN as solvent, and $\mathrm{T}=$ 298 K. See Figure 1 and Figure 2 for the labels of all compounds.

\begin{tabular}{|c|c|c|c|c|c|c|}
\hline \multirow[b]{2}{*}{ Benzoic (4a) } & \multicolumn{6}{|c|}{$\mathrm{pK}_{\mathrm{a}}$} \\
\hline & \multicolumn{6}{|c|}{$\begin{array}{c}(20.10 / 20.70)^{\mathrm{b},[38]} \\
20.32 / 20.58^{[39]} ; 21.24^{[40]} ; 21.09 / 21.51 / 22.14^{[41]} \\
21.31\end{array}$} \\
\hline & \multicolumn{3}{|c|}{$\mathrm{pK}_{\mathrm{a}, 1}$} & \multirow{2}{*}{\multicolumn{3}{|c|}{$\mathrm{pK}_{\mathrm{a}, 2}$}} \\
\hline & Ortho & meta & para & & & \\
\hline Carborane carboxylic & $\begin{array}{c}(\mathbf{1 a}) \\
12.64\end{array}$ & $\begin{array}{c}(\mathbf{2 a}) \\
15.70^{\mathrm{d}}\end{array}$ & $\begin{array}{c}(\mathbf{3 a}) \\
15.92^{\mathrm{d}}\end{array}$ & Ortho & meta & Para \\
\hline Phthalic & $\begin{array}{c}(\mathbf{5 c}) \\
14.3^{\mathrm{b},[40]} \\
17.01^{[40]} \\
11.90\left(19.36^{\mathrm{c}}\right)\end{array}$ & $\begin{array}{c}(\mathbf{6 c}) \\
19.3^{b,[40]} \\
20.03^{[40]} \\
19.78\end{array}$ & $\begin{array}{c}(7 \mathbf{c}) \\
19.7^{\mathrm{b},[40]} \\
19.8^{[40]} \\
19.49\end{array}$ & $\begin{array}{c}(\mathbf{5 d}) \\
31.75\left(24.29^{\mathrm{c}}\right)\end{array}$ & $\begin{array}{c}(\mathbf{6 d}) \\
23.36\end{array}$ & $\begin{array}{c}(7 d) \\
22.93\end{array}$ \\
\hline
\end{tabular}




\begin{tabular}{lcccccc} 
& $(\mathbf{1 c})$ & $\mathbf{( 2 c})$ & $(\mathbf{3 c})$ & $(\mathbf{1 d})$ & $(\mathbf{2 d})$ & $\mathbf{( 3 d})$ \\
Carborane dicarboxylic & $4.68\left(10.74^{c}\right)$ & 14.14 & 15.60 & $23.76\left(17.70^{c}\right)$ & 16.79 & 18.12 \\
\hline
\end{tabular}

\footnotetext{
${ }^{\mathrm{a}} \mathrm{pK}_{\mathrm{a}} \mathrm{s}$ using computed Gibbs energies of the optimized structures in $\mathrm{MeCN}$

${ }^{\mathrm{b}}$ Experimental values

${ }^{\mathrm{c}}$ Alternative monocarboxylate structure without intramolecular hydrogen bond

${ }^{\mathrm{d}}$ Using optimized geometries in the gas phase
}

The ortho-carborane carboxylic acid (1a) is ca. $9 \mathrm{pK}_{\mathrm{a}}$ units more acidic than benzoic acid. As in gas phase, 1a is largely more acidic than the meta (2a) and para isomers (3a), ca. four $\mathrm{pK}_{\mathrm{a}}$ units. A similar trend is observed when comparing the first ionization $\left(\mathrm{pK}_{\mathrm{a}, 1}\right)$ of phthalic acids and carborane dicarboxylic acids. The presence of the second carboxylic group enhances the acidity, to a much larger extent for the ortho isomer (1c) - as in the gas phase - due to the contribution of the carboxylate ion stabilized by intramolecular hydrogen bonding, as shown in Figure 5. The ortho-carborane dicarboxylic acid (1c) will also behave as a superacid in the liquid phase $(\mathrm{MeCN})$, since the computed $\mathrm{pK}_{\mathrm{a}}(c a .4 .7)$ - see Table 3 - is lower than the $\mathrm{pK}_{\mathrm{a}}$ of $\mathrm{H}_{2} \mathrm{SO}_{4}$ measured in acetonitrile (ca. 7.3) [42].

Turning now to the substitution of the carborane cage (3D) by a benzene ring (2D), the computed $\mathrm{pK}_{\mathrm{a}, 1}$ for phthalic acid (5c) is different from that measured in the lab, although its higher acidity than in isophthalic (6c) and terephthalic (7c) acids is properly predicted. Taking into account the experimental value of phthalic acid, it could be expected that the $\mathrm{pK}_{\mathrm{a}, 1}$ of the ortho-carborane dicarboxylic acid (1c) should be lower $c a$. 6.5 units. A value of $\mathrm{pK}_{\mathrm{a}, 1} c a .9$ can be expected, taking into account the decrease when moving from isophthalic(6c)/terephthalic(7c) acids to phthalic acid. This $\mathrm{pK}_{\mathrm{a}, 1}$ approaches to 6.5 as the energy rise, due to the benzene ring distortion by the formation of the intramolecular hydrogen bonding in phthalic monocarboxylate (5d) - Figure 5 which does not appear in the ortho-carborane monocarboxylate (1d), and the acidifying effect of the carborane cage. Again, a larger cage $\mathrm{C} \cdots \mathrm{C}$ distance (Figure 5) provides an enhanced stabilization for the carboxylate [44]. Notice that the hydrogen and oxygen atoms involved in the intramolecular hydrogen bond do not lie on the same plane of the benzene ring carbon atoms, as shown in Figure 5. Selected geometrical parameters of the optimized structures of the monocarboxylate of phthalic acid (5c) and orthocarborane dicarboxylic acid (1c) are collected in Table S1 of the Supplementary Information. Table 3 also includes the $\mathrm{pK}_{\mathrm{a}, 1}$ values for ortho dicarboxylic acids, both 
phthalic and carborane, in absence of intramolecular hydrogen bond. If we take a structure without hydrogen intramolecular interaction, the acidity of phthalic isomers is almost the same, whereas in ortho-carborane dicarboxylic acid (1c) appears to be more acid than the meta (2c) and para isomers (3c). Hence, the carborane cage effect is also valid in the liquid phase, and the $\mathrm{pK}_{\mathrm{a}, 1} \mathrm{~s}$ for carborane acids are lower than in the phthalic analogues.

The pattern for the second deprotonation $\left(\mathrm{pK}_{\mathrm{a}, 2}\right)$ is similar for phthalic (5d-7d) and carborane dicarboxylic acids, meta (2d) and para (3d) isomers more acidic than ortho (1d), again as a result of the intramolecular hydrogen interaction in orthomonocarboxylates - Figure 5, thus explaining the order relation $\mathrm{pK}_{\mathrm{a}, 2}$ ortho $>>\mathrm{pK}_{\mathrm{a}, 2}{ }^{\text {meta }}$, $\mathrm{pK}_{\mathrm{a}, 2}^{\text {para }}$. The carborane dicarboxylic acids $(\mathbf{1 d - 3 d})$ are more acidic than phthalic acids (5d-7d) by ca. six $\mathrm{pK}_{\mathrm{a}}$ units. These $\mathrm{pK}_{\mathrm{a}, 2}$ values should be considered with caution since the quantum-chemical computation of solvated doubly charged anions is less reliable as compared to monovalent anions [43].

The explanation for the superacidity of $\mathbf{1 c}$ as compared to $\mathbf{5 c}$ - both in the gas phase and liquid phase - is clearly due to the enhanced stability of the carboxylate anion 1d, originating from the longer $\mathrm{C}_{1}-\mathrm{C}_{2}$ bond [44] in the carborane 1c as compared to the shorter $\mathrm{C}_{1}-\mathrm{C}_{2}$ bond in phthalic acid $\mathbf{5 c}$, and the electron-acceptor nature of polyhedral (car)boranes [45].

\subsection{Delocalization energies.}

How do electrons delocalize in carborane carboxylic (1a-3a) and dicarboxylic acids (1c3c)? In order to answer this question we will compare the delocalization in these systems with those in benzoic (4) and phthalic acids (5-7), as we did for GAs and $\mathrm{pK}_{\mathrm{a}} \mathrm{s}$ in the previous sections. The delocalization can be addressed in general cases with a variety of methods such as the standard Natural Bond Orbital analysis (NBO) - with second order terms $[46,47]$ or specifically designed approaches with strong localization constraints such as the ALMO-EDA method (absolutely localized molecular orbital Energy Decomposition Analysis) [48] or the block-localized wavefunction analysis (BLW) [49]. We use the latter in a very standard way by comparing the situation where the four $\pi$ electrons of the $\mathrm{COOH}$ carboxylic acid moieties are kept local in the $\pi$ orbitals that are located on the acid moieties, with respect to the situation where all 
electrons delocalize. A similar strategy is used for the other cases [50]. From these two computations we retrieve the energy and electron density in order to compute the "Vertical Delocalization Energy" and the electronic density difference respectively. Such density differences are plotted with the VMD program [51].

We also take into account the isomerization energy with respect to the more stable para isomer:

$$
\operatorname{Isom}(\boldsymbol{n} \boldsymbol{x})=\mathrm{E}(\boldsymbol{n} \boldsymbol{x})-\mathrm{E}(\mathbf{3} \boldsymbol{x}), \boldsymbol{n}=\mathbf{1}, \mathbf{2} \text { and } \boldsymbol{x}=\mathbf{a}, \mathbf{b}, \mathbf{c}
$$

A positive isomerization energy for $\boldsymbol{n} \boldsymbol{x}$ means that this isomer is less stable than the para isomer $3 \boldsymbol{x}$. Such an isomerization energy can be calculated with energies of standard (delocalized) computations (labeled "Isom Deloc"), or with localization constrains (labeled "Isom Loc $)$.

\subsubsection{Carborane carboxylic and dicarboxylic acids}

The VDE values for these systems are displayed in Table 4, and organized in two different groups: one concerning a carboxylic acid, $\mathrm{COOH}$ delocalization (1a-3a, 1c-3c, and 1d-3d) and that of a carboxylate base $\mathrm{COO}(-)$. Except for 1d, which embeds some spurious terms (vide infra), the carboxylic acid delocalization energy amounts to 28-32 $\mathrm{kJ} / \mathrm{mol}$, while the $\mathrm{COO}(-)$ value is about half of that $(17-19 \mathrm{~kJ} / \mathrm{mol})$. In the Figures corresponding to this section, the green/red areas correspond to an increase/decrease of the density when the electron localization constrain is released. The plot of the electronic density difference map for the cases 3a and $\mathbf{3 b}$ (Figure 6) show the characteristic delocalization pattern, from the $\mathrm{C}-\mathrm{B}$ bonds of the carborane cage to the $\mathrm{C}-\mathrm{C}$ bond that links the carborane to the carboxy group. This contributes to strengthen the $\mathrm{C}-\mathrm{C}$ bond as a kind partial of $\pi$ double bond as shown by the shape of the green parts of the electronic density difference. It is also shown that the donation from the carborane is much smaller for the anion. Therefore the $\mathrm{COO}(-)$ moiety has a larger contribution to this partial $\pi$ double bond, being consistent with the fact that $\mathrm{COO}(-)$ is $a$ priori a better donating group than $\mathrm{COOH}$.

Other delocalization (edd) maps are depicted in Figure 7. The pattern always corresponds to that already shown in Figure 6. Only isomer 1d differs: its delocalization pattern is much larger than in other cases, and the $\mathrm{COOH}$ part clearly borrows some additional electronic density from the neighbouring $\mathrm{COO}(-)$ moieties, thus resulting in a 
larger delocalization energy (67 kJ/mol - Table 4). The isomerization energies (Isom Loc and Isom $_{\text {Deloc }}$ in Table 4) show an explanation about this difference: isomerization energies usually do not depend on the localization constraint: Isom $_{\text {Loc }}($ label $) \approx$ $\operatorname{Isom}_{\text {Deloc }}($ label $) \pm 4$. Only for $1 \mathbf{d}$ the values are different: $\operatorname{Isom}_{\text {Loc }}(1 \mathbf{d}) \approx \operatorname{Isom}_{\text {Loc }}(1 \mathbf{a}) \approx 74$ $\mathrm{kJ} / \mathrm{mol}$ but $\operatorname{Isom}_{\text {Deloc }}(\mathbf{1 d})$ is much smaller, $40.1 \mathrm{~kJ} / \mathrm{mol}$, than $\operatorname{Isom}_{\text {Deloc }}(\mathbf{1 a})$. This validates the computation with localization constraint and proves that the delocalization matters for the stability of the anion in the case where both functions are close enough to allow some additional electronic delocalization.

Table 4. Vertical delocalization energies (VDE) and isomerization energies (Isom Loc $_{\text {. }}$ and $\mathbf{I s o m}_{\text {Deloc }}$ ) for various carborane cases, in $\mathrm{kJ} / \mathrm{mol}$. The isomerization energies are computed with respect to the para isomer, which is always the more stable. Both the localized and the delocalized wave functions are used for the isomerization energy, they are labelled accordingly. Absolute energies $\left(\mathrm{E}_{\text {Localized }}\right.$ and $\left.\mathrm{E}_{\text {Delocalized }}\right)$ are given in atomic units (Hartree). Labels according to Figure 1.

\begin{tabular}{cccccc}
\hline Labels & VDE & Isom $_{\text {Loc }}$ & Isom $_{\text {Deloc }}$ & $\mathbf{E}_{\text {Localized }}$ & $\mathbf{E}_{\text {Delocalized }}$ \\
\hline $\mathbf{( 1 a )}$ & -30.4 & 73.0 & 70.6 & -520.40815 & -520.41974 \\
$\mathbf{( 2 a )}$ & -28.6 & 12.1 & 11.6 & -520.43134 & -520.44222 \\
$\mathbf{( 3 a )}$ & -28.0 & $\mathbf{0 . 0}$ & $\mathbf{0 . 0}$ & -520.43596 & -520.44662 \\
\hline $\mathbf{( 1 b )}$ & -18.4 & 24.6 & 23.9 & -519.90800 & -519.91499 \\
$\mathbf{( 2 b )}$ & -17.8 & 1.1 & 0.9 & -519.91695 & -519.92373 \\
$\mathbf{( 3 b )}$ & -17.6 & $\mathbf{0 . 0}$ & $\mathbf{0 . 0}$ & -519.91738 & -519.92409 \\
\hline $\mathbf{( 1 c )}$ & -30.7 & 89.1 & 86.2 & -708.93602 & -708.94772 \\
$\mathbf{( 2 c )}$ & -28.1 & 13.2 & 12.9 & -708.96493 & -708.97564 \\
$\mathbf{( 3 c )}$ & -27.8 & $\mathbf{0 . 0}$ & $\mathbf{0 . 0}$ & -708.96996 & -708.98054 \\
\hline $\mathbf{( 1 d )}$ & -23.8 & -14.9 & -6.0 & -708.45583 & -708.46489 \\
$\mathbf{( 2 d )}$ & -32.0 & 2.3 & 2.9 & -708.44930 & -708.46149 \\
$\mathbf{( 3 d )}$ & -32.6 & $\mathbf{0 . 0}$ & $\mathbf{0 . 0}$ & -708.45017 & -708.46258 \\
\hline $\mathbf{( 1 e )}$ & -20.4 & 87.5 & 85.5 & -707.81049 & -707.81827 \\
$\mathbf{( 2 e )}$ & -18.5 & 7.0 & 6.8 & -707.84118 & -707.84824 \\
$\mathbf{( 3 e )}$ & -18.4 & $\mathbf{0 . 0}$ & $\mathbf{0 . 0}$ & -707.84383 & -707.85082 \\
\hline
\end{tabular}




\subsubsection{Benzoic and phthalic acids}

The delocalization energies computed for the carborane cases can be compared to those from benzoic and phthalic acids. Table 5 shows the results obtained for the latter. We show that (as for carboranes) the delocalization energy is larger for the carboxylic $\mathrm{COOH}$ moiety (more than $45 \mathrm{~kJ} / \mathrm{mol}$ ) than in the carboxylate COO(-) $(28 \mathrm{~kJ} / \mathrm{mol})$. The density differences shown in Figure 8 are also (consistently) smaller for the anion $\mathrm{COO}(-)$. It is clear from Table 5 that the pattern is similar for the di-substituted cases; the neutral dicarboxylic acids (5c-7c) have a larger delocalization energy (about 45 $\mathrm{kJ} / \mathrm{mol}$ ) compared to carboxylate anions (5d-7d), about $28 \mathrm{~kJ} / \mathrm{mol}$. As shown in Figure 8 and Figure 9, the donation takes place again from the cycle to the direction of the $\mathrm{COOH}$ or $\mathrm{COO}(-)$ moiety. The energy difference between the isomer shows that the ortho isomer is strongly disfavoured (by $30 \mathrm{~kJ} / \mathrm{mol}$ ).

Table 5. Vertical delocalization energies (VDE) and isomerization energies ( Isom $_{\text {Loc }}$ and $\mathbf{I s o m}_{\text {Deloc }}$ ) for various benzoic acid cases. See Table 4.

\begin{tabular}{llllll}
\hline Labels & VDE & Isom $_{\text {Loc }}$ & Isom $_{\text {Deloc }}$ & $\mathbf{E}_{\text {Localized }}$ & $\mathbf{E}_{\text {Delocalized }}$ \\
\hline $\mathbf{4 a}$ & -47.6 & & & -420.68288 & -420.70102 \\
$\mathbf{4 b}$ & -28.0 & & & -420.14515 & -420.1558 \\
\hline $\mathbf{5 c}$ & -43.5 & 29.9 & 31.6 & -609.22215 & -609.23873 \\
$\mathbf{6 c}$ & -45.7 & -1.1 & -1.5 & -609.23395 & -609.25134 \\
$\mathbf{7 c}$ & -45.3 & $\mathbf{0 . 0}$ & $\mathbf{0 . 0}$ & -609.23352 & -609.25078 \\
\hline $\mathbf{5 d}$ & -44.4 & -14.9 & -31.2 & -608.71132 & -608.72823 \\
$\mathbf{6 d}$ & -27.4 & 2.7 & 3.5 & -608.70460 & -608.71503 \\
$\mathbf{7 d}$ & -28.1 & $\mathbf{0 . 0}$ & $\mathbf{0 . 0}$ & -608.70564 & -608.71635 \\
\hline $\mathbf{5 e}$ & -34.3 & 115.2 & 111.1 & -608.02513 & -608.03819 \\
$\mathbf{6 e}$ & -28.7 & 19.9 & 21.4 & -608.06140 & -608.07235 \\
$\mathbf{7 e}$ & -30.2 & $\mathbf{0 . 0}$ & $\mathbf{0 . 0}$ & -608.06900 & -608.08050 \\
\hline
\end{tabular}




\section{Conclusions}

The computed gas-phase acidities (GA) and liquid-phase acidities $\left(\mathrm{pK}_{\mathrm{a}}\right)$ for carboxylic and dicarboxylic acids derived from icosahedral carboranes (1a-3a, 1c-3c) show the following points:

(1) Cage effect : Striking increase of acidity when substituting a benzene ring (phthalic acids) by an icosahedral carborane cage.

(2) Isomer effect: The ortho isomer is always the most acidic due to enhanced stability of the carboxylate thru $\mathrm{O} \cdots \mathrm{H} \cdots \mathrm{O}$ bridge interactions.

(3) Acidities always follow the order relation ortho $>>$ meta $>$ para.

(4) We predict that the ortho-carborane dicarboxylic acid 1,2-(COOH $)_{2}-1,2-$ $\mathrm{C}_{2} \mathrm{~B}_{10} \mathrm{H}_{10}$, labelled as $1 \mathrm{c}$ in this work, is a superacid in the gas phase, with a GA far beyond $\mathrm{H}_{2} \mathrm{SO}_{4}$. The same applies for $1 \mathrm{c}$ in the liquid-phase $(\mathrm{MeCN})$, since the $\mathrm{pK}_{\mathrm{a}}$ is nearly 2.5 units lower than the $\mathrm{pK}_{\mathrm{a}}$ of $\mathrm{H}_{2} \mathrm{SO}_{4}$.

(5) Electron delocalization energy computations support the features described in the above points.

Finally, having achieved the synthesis of the dicarboxylic acids $1 \mathbf{c}, \mathbf{2 c}$ and $\mathbf{3 c}$ at the

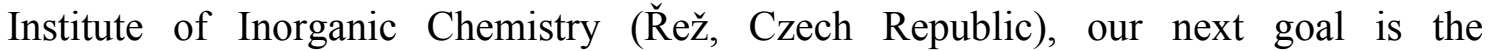
experimental determination of their gas-phase and liquid-phase acidities. On the Hammett scale sulphuric acid has $\mathrm{H}_{0}=-12$, the onset of superacidity in solution. The protonation of benzene is a benchmark of superacidity above. For instance, triflic acid $\left(\mathrm{H}_{0}=-14\right)$ doest not protonate benzene, whereas carboranes do, thus indicating that Hammett acidities of carboranes should be around -17 or even larger in absolute value: $\mathrm{H}_{0}$ (carboranes) $\leq-17$. Therefore the interaction between non-conventional acids, like the ones included in this work, may open new directions in the prediction of unusual reaction mechanisms between heteroborane compounds and molecules of interest in emerging scientific and technological research fields.

\section{Acknowledgments}


Y. Mo is gratefully acknowledged for the BLW code, which was used for the computation of electronic delocalization effects. J.A.S.L. and M.C.L. are grateful to Centro de Supercomputación de Galicia (CESGA) for computing facilities and Xunta de Galicia for financial support (Consolidación e estruturación de unidades de investigación competitivas do sistema galego de I+D+I (2017 GPC - ED431B 2017/59). I.A. acknowledges Ministerio de Economía y Competitividad (Grant CTQ2015-63997C2-2-P) and Comunidad Autónoma de Madrid (Grants Fotocarbon and S2013/MIT2841).

Note: Supporting Information, Tables $1 \& 2$ and Figures 1-4 are included as different files.

\section{FIGURES}
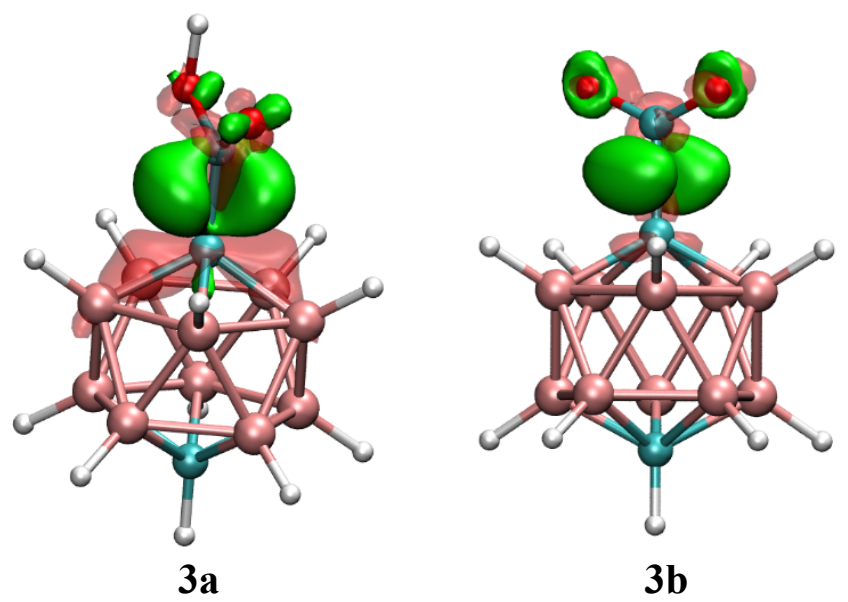

Figure 6. Electron density difference (edd) drawings for the para-carborane carboxylic acid 3a (left) showing a donation from the neighbouring $\mathrm{C}-\mathrm{B}$ bond to the $\mathrm{C}-\mathrm{C}$ bond. (Right) Edd plot for the corresponding carboxylate $\mathbf{3 b}$. We plot in green the areas where the density increases when the electron localization constrain is released, and in translucent red those where it decreases. Isosurfaces represented correspond to $\pm 5 \times 10^{-}$ ${ }^{4}$ au. 


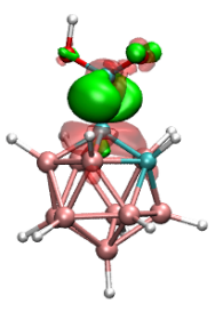

$1 a$

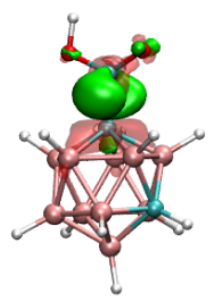

$2 a$

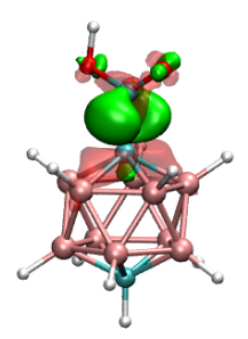

3a

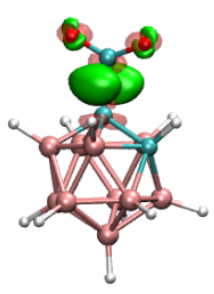

1b

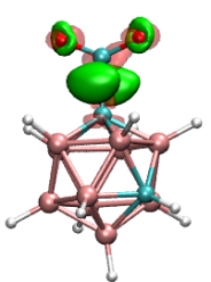

2b

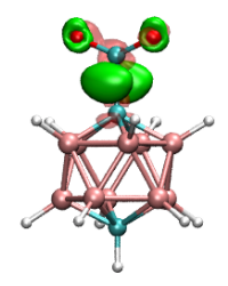

3b

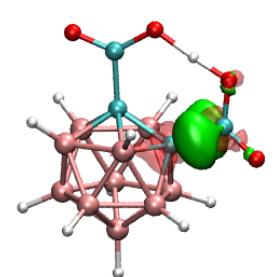

1c

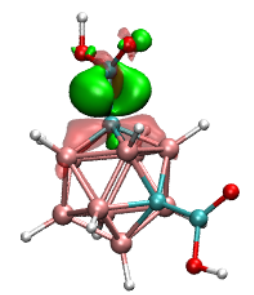

2c

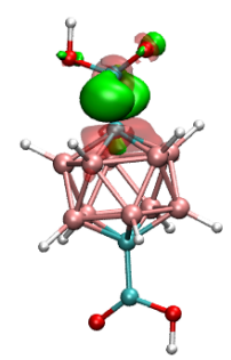

$3 c$

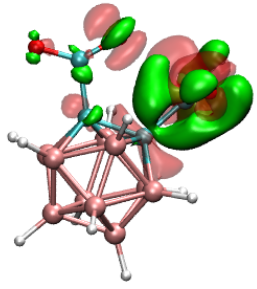

1d

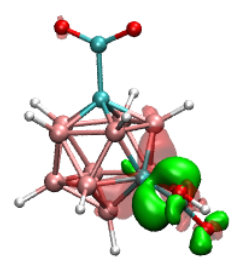

2d

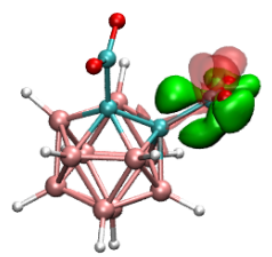

1e
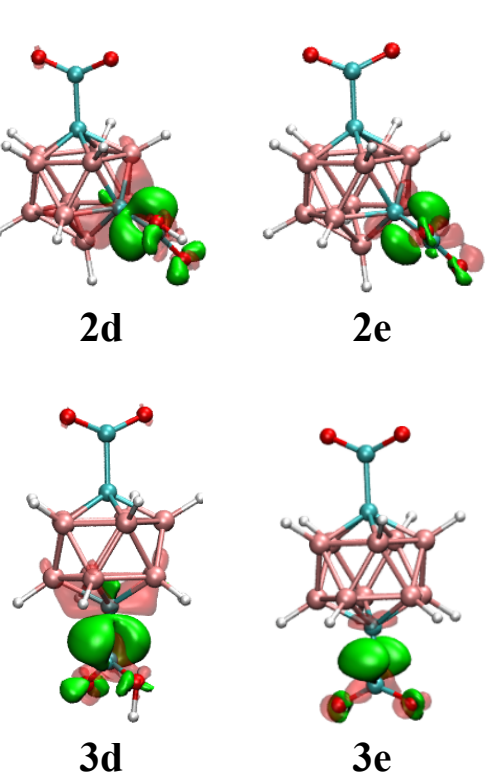
Figure 7. Electron density difference (edd) drawings for the carboranes (carboxylic and dicarboxylic acids). We plot in green the areas where the density increases when the electron localization constrain is released, and in translucent red those where it decreases. Isosurfaces represented correspond to $\pm 5 \times 10^{-4}$ au.

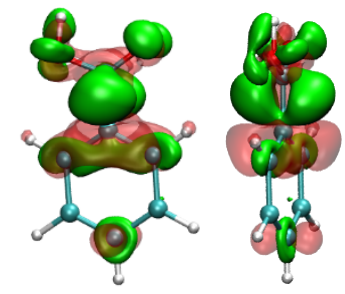

$4 a$

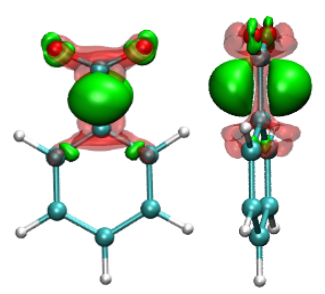

4b

Figure 8. Electron density difference (edd) drawings for the benzoic acid 4a (left) showing a donation from the neighbouring benzoic ring to the $\mathrm{C}-\mathrm{C}$ bond. The donation is smaller for the anion $\mathbf{4 b}$ (right). We plot in green the areas where the density increases when the electron localization constrain is released, and in translucent red those where it decreases. Isosurfaces represented correspond to $\pm 5 \times 10^{-4}$ au. 


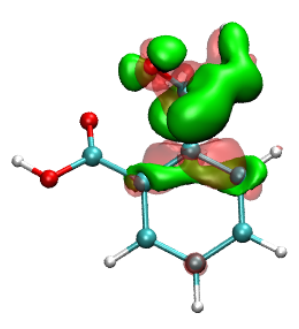

5c

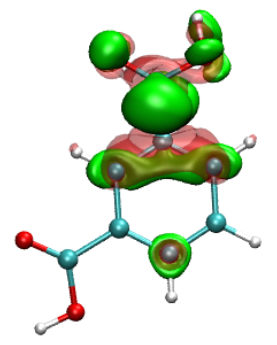

$6 c$

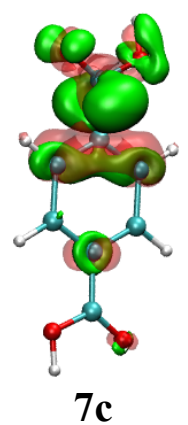

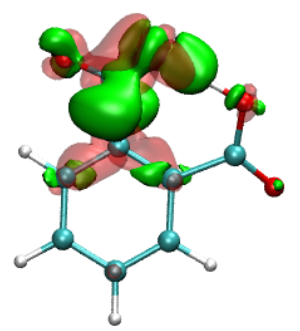

5d

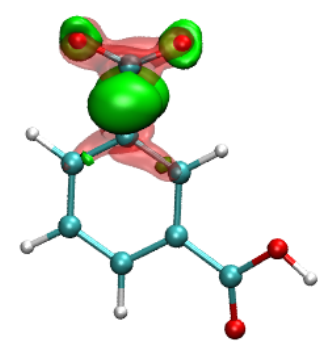

6d

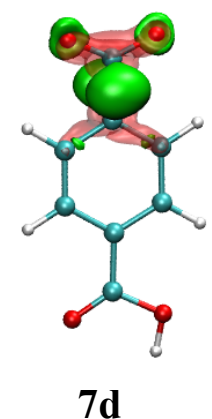

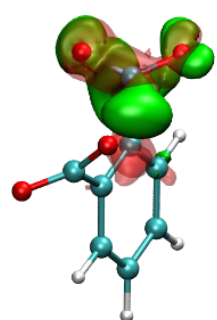

$5 e$

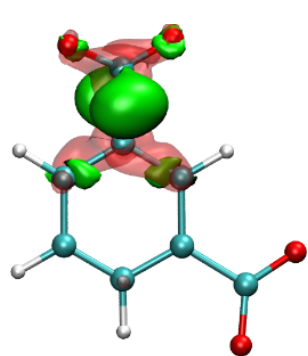

$6 e$

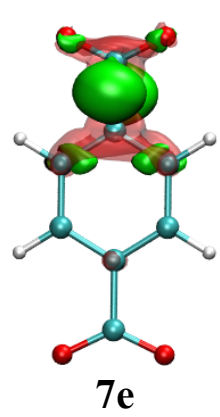

Figure 9. Electron density difference (edd) drawings for the benzoic diacids in ortho, meta, para position $(\mathbf{5 c}, \mathbf{6 c}, \mathbf{7 c})$, the corresponding anions $(\mathbf{5 d}, \mathbf{6 d}, \mathbf{7 d})$ and dianions $(\mathbf{5 e}$, $\mathbf{6 e}, 7 \mathbf{e})$. We plot in green the areas where the density increases when the electron localization constrain is released, and in translucent red those where it decreases. Isosurfaces represented correspond to $\pm 5 \times 10^{-4}$ au. 


\section{References}

1 Within electron-tranfer we may include proton/hydride/hydrogen-transfer reactions. In summary $\left[\mathrm{e} / \mathrm{H}^{+} / \mathrm{H}^{-} / \mathrm{H}\right]$-transfer.

2 (2012) Organic Chemistry, J. Clayden, N. Greeves and S. Warren. Oxford University Press, pp. 1-15.

CRC Handbook of Chemistry and Physics, 98th Edition, CRC Press, 2017, ISBN 9781498784542.

${ }^{4} \mathrm{~A}$ heteroborane is based on a polyhedral borane $\mathrm{B}_{\mathrm{n}} \mathrm{H}_{\mathrm{m}}$ where one or more of the boron atoms is substituted by another atom of the Periodic Table.

${ }_{5}$ Boron - the Fifth Element. Challenges and Advances in Computational Chemistry and Physics, ed. D. Hnyk and M. McKee, Springer, Heidelberg, New York, Dordrecht and London, 2015.

${ }^{6}$ (a) E. Bernhardt, D. J. Brauer, M. Finze and H. Willner, Angew. Chem. 2007, 119, 2985-2988; (b) Angew. Chem. Int. Ed. 2007, 46, 2927-2930.

${ }^{7}$ S. M. Eyrilmez, E. Bernhardt, J. Z. Dávalos, M. Lepšík, P. Hobza, K.I. Assaf, W.M. Nau, J. Holub, J. M. Oliva-Enrich, J. Fanfrlík, D. Hnyk, Phys. Chem. Chem. Phys., 2017, 19, 1174811752.

${ }^{8}$ Strictly speaking, the IUPAC defines the gas-phase acidity (GA) as the negative of the Gibbs energy change $\left(\Delta_{\mathrm{r}} \mathrm{G}^{0}\right)$ for the reaction $\mathrm{A}-\mathrm{H} \rightarrow \mathrm{A}^{-}+\mathrm{H}^{+}$. In this work we use a positive value of $\mathrm{GA}=\Delta_{\mathrm{r}} \mathrm{G}^{0}$ with the rule that the lower the GA, the more acidic the system.

${ }^{9}$ A. A. Viggiano, M. J. Henchman, F. Dale, C. A. Deakyne, J. F. Paulson, J. Am. Chem. Soc., 1992, 114, 11, 4299-4306.

${ }^{10}$ C. Jene, M. Keßler, J. Warneke, Chem. Eur. J., 2015, 21, 5887-5891.

${ }^{11}$ L. Lipping, I. Leito, I. Koppel, I. Krossing, D. Himmel, I.A. Koppel, J. Phys. Chem. A, 2015, 119, 735-743.

${ }^{12}$ A. Avelar, F.S. Tham and C.A. Reed, Angew. Chem. Int. Ed. 2009, 48, 3491-3493.

${ }^{13}$ C. A. Reed, K.-C. Kim, E. S. Stoyanov, D. Stasko, F. S. Tham, L. J. Mueller and P. D.W. Boyd, J. Am. Chem. Soc., 2003, 125, 1796-1804.

${ }^{14}$ C. A. Reed, Chem. Commun., 2005, 1669-1677.

${ }^{15}$ M. M. Meyer, X. B. Wang, C. A. Reed, L. S. Wang and S. R. Kass, J. Am. Chem. Soc., 2009, 131, 18050-18051.

${ }^{16}$ S. J. Grabowski, Phys. Chem. Chem. Phys., 2016, 24, 16152-16160.

${ }^{17}$ The concept of Brønsted acidity was initially defined by Brønsted and Lowry in 1923 for aqueous solutions: a) J. N. Brønsted, Recl. Trav. Chim. Pay-Bas, 1923, 42, 718-728, b) T. M. Lowry, Chem. Ind., 1923, 42, 43-47.

${ }^{18}$ L. P. Hammett and A. J. Deyrup, J. Am. Chem. Soc., 1932, 54, 2721-

${ }^{19}$ L. P. Hammett, Physical Organic Chemistry, 1940, McGraw-Hill.

${ }^{20}$ P. D. Pancharatna, M. M. Balakrishnarajan, E. D. Jemmis, R. Hoffmann, J. Am. Chem. Soc., 2012, 134, 5916-5920.

${ }^{21}$ J. Z. Dávalos, J. González, R. Ramos, D. Hnyk, J. Holub, J. A. Santaballa, M. Canle-L. and J. M. Oliva, J. Phys. Chem. A, 2014, 118, 2788-2793.

${ }^{22}$ Gaussian 09, Revision D.01, M. J. Frisch, G. W. Trucks, H. B. Schlegel, G. E. Scuseria, M. A. Robb, J. R. Cheeseman, G. Scalmani, V. Barone, G. A. Petersson, H. Nakatsuji, X. Li, M. Caricato, A. Marenich, J. Bloino, B. G. Janesko, R. Gomperts, B. Mennucci, H. P. Hratchian, J. V. Ortiz, A. F. Izmaylov, J. L. Sonnenberg, D. Williams-Young, F. Ding, F. Lipparini, F. Egidi, J. Goings, B. Peng, A. Petrone, T. Henderson, D. Ranasinghe, V. G. Zakrzewski, J. Gao, N. Rega, G. Zheng, W. Liang, M. Hada, M. Ehara, K. Toyota, R. Fukuda, J. Hasegawa, M. Ishida, T. Nakajima, Y. Honda, O. Kitao, H. Nakai, T. Vreven, K. Throssell, J. A. Montgomery, Jr., J. E. Peralta, F. Ogliaro, M. Bearpark, J. J. Heyd, E. Brothers, K. N. Kudin, V. N. Staroverov, T. Keith, R. Kobayashi, J. Normand, K. Raghavachari, A. Rendell, J. C. Burant, S. S. Iyengar, J. Tomasi, M. Cossi, J. M. Millam, M. Klene, C. Adamo, R. Cammi, J. W. Ochterski, R. L. 
Martin, K. Morokuma, O. Farkas, J. B. Foresman and D. J. Fox, Gaussian, Inc., Wallingford CT, 2016.

${ }^{23}$ C. Møller and M. S. Plesset, Phys. Rev., 1934, 46, 618-622.

${ }^{24}$ A. D. Becke, Phys. Rev. A, 1988, 38, 3098-100.

${ }^{25}$ C. Lee, W. Yang and R. G. Parr, Phys. Rev. B, 1988, 37, 785-789.

${ }^{26}$ B. T. Psciuk, R. L. Lord, B. H. Munk and H. B. Schlegel, J. Chem. Theory Comput., 2012, 8, $5107-5123$

${ }^{27}$ A. V. Marenich. C. J. Cramer and D. G. Truhlar, J. Phys. Chem. B, 2009, 113, 6378-6396.

${ }^{28}$ D. A. McQuarrie, Statistical Mechanics, Harper and Row, New York, 1973.

${ }^{29}$ E. Rossini and E.-W. Knapp, J. Comp. Chem., 2016, 37, 1082-1091.

${ }^{30}$ Y. Mo, L. Song and Y. Lin, J. Phys. Chem. A, 2007, 111, 8291-8301.

${ }^{31}$ M. W. Schmidt, K. K. Baldridge, J. A. Boatz, S. T. Elbert, M. S. Gordon, J. H. Jensen, S. Koseki, N. Matsunaga, K. A. Nguyen, S. J. Su, T. L. Windus, M. Dupuis and J. A. Montgomery, J. Comput. Chem. 1993, 14, 1347-1363.

${ }^{32}$ R. Krishnan, J. S. Binkley, R. Seeger and J. A. Pople, J. Chem. Phys. 1980, 72, 650-654.

${ }^{33}$ S. H. Vosko, L. Wilk and M. Nusair, Can. J. Phys., 1980, 58, 1200-1211.

${ }^{34}$ A. W. Laubengaye and W.R. Rysz, Inorg. Chem., 1965, 4, 1513-1514.

${ }^{35}$ It was shown by using simple vector algebra of the experimentally determined dipole moment that the center of C-C distance is positively charged, see: D. Hnyk, V. Všetečka, L. Drož and O. Exner, Collect. Czech. Chem. Commun., 2001, 66, 1375-1379.

${ }^{36}$ J. F. Coetzee, Prog. Phys. Org. Chem., 1967, 4, 45-92.

${ }^{37}$ I. M. Kolthoff and M. K. Chantooni Jr, J. Phys. Chem., 1968, 72, 2270-2272.

${ }^{38}$ I. M. Kolthoff and M. K. Chantooni Jr., J. Phys. Chem., 1966, 70, 856-866.

${ }^{39}$ F. Ding, J. M. Smith, H. Wang, J. Org. Chem., 2009, 74, $2679-2691$.

${ }^{40}$ F. Eckert, I. Leito, I. Kaljurand, A. Kütt, A. Klamt and M. Diedenhofen, J. Comp. Chem., $2008,30,799-810$.

${ }^{41}$ J. T. Muckerman, J. H. Skone, M. Ning and Y. Wasada-Tsutsui. Biochim. Biophys. Acta, 2013, 1827, 882-891.

${ }^{42}$ I. M. Kolthoff, S. Bruckenstein, M. K. Chantooni Jr., J. Am. Chem. Soc., 1961, 83, 39273935.

${ }^{43}$ A. V. Marenich, W. Ding, C. J. Cramer, D. G. Truhlar, J. Phys. Chem. Lett. 2012, 3, $1437-1442$.

${ }^{44}$ J. M. Oliva, N. L. Allan, P.V. Schleyer, C. Viñas, F. Teixidor, J. Am. Chem. Soc., 2005, 127, 13538-13547.

${ }^{45}$ R. N. Grimes, in Carboranes, $3^{\text {rd }}$ ed, Academic Press 2106.

${ }^{46}$ E. D. Glendening, C. R. Landis and F. Weinhold, WIREs Comput. Mol. Sci., 2012, 2, 1-42.

${ }^{47}$ E. D. Glendening, C. R. Landis and F. Weinhold, J. Comput. Chem., 2013, 34, 1429-1437.

${ }^{48}$ R. Z. Khaliullin, E. A. Cobar, R. C. Lochan, A. T. Bell and M. Head-Gordon, J. Phys. Chem. $A, 2007,111,8753-8765$.

${ }^{49}$ Y. Mo and S. D. Peyerimhoff, J. Chem. Phys., 1998, 109, 1687-1697.

${ }^{50}$ J. Racine and S. Humbel, Chem. Eur. J., 2014, 20, 12601-12606.

${ }^{51}$ A. Dalke and K. Schulten J. Mol. Graph., 1996, 14, 33-38.

http://www.ks.uiuc.edu/Research/vmd/ 